\title{
The AMLEV Technology Applied to Low Speed Urban Transportation Systems
}

\author{
G. Lutzemberger, A. Musolino, R. Rizzo, and L. Sani \\ DESTEC-Department of Energy and Systems Engineering \\ University of Pisa, Italy
}

\begin{abstract}
The American version of Maglev (AMLEV) was developed in the USA since 1992. It is based on the interaction between a system of permanent magnets (PMs) installed on the vehicle, and steel cores positioned along the guideway. By using an analytical model, the inventor demonstrated that the system was able to produce levitating and stabilizing forces, allowing to safely reach a speed up to $150 \mathrm{~m} / \mathrm{s}$. In the present paper, the AMLEV technology is firstly simulated by using a FEM model; then its possible application in a low speed urban transportation system is verified. Finally, a comparison in terms of energy consumption and braking energy recovery efficiency is performed.
\end{abstract}

Keywords-Maglev systems; urban transportation systems; FEM simulations;

\section{INTRODUCTION}

An urban transportation system (UTS) usually transports passengers point to point with high frequency and capacity. It is based on light vehicles (in the range between $4.000-20.000 \mathrm{~kg}$ of empty mass) which run along a dedicated guideway. The conventional UTS uses wheel-on-rail or wheel-on-route systems and rotating electrical motors for the propulsion. Anyhow, in order to improve the performance and to reduce the operating costs of these systems, the maglev technology can be applied in this field. Even though many worldwide attempts have been proposed [1]-[3] in the past, the maglev urban transportation systems are not so common due to two main causes. The first one is the difficulty of companies in adopting innovative solutions that are still poorly mature and reliable and with too high investment costs; the second cause is the lack of simple, flexible, and cost-effective technical solutions that compete both from the point of view of performance and cost with conventional UTSs. In the past decades, some maglev solutions have been presented, which seem appealing to develop reliable, simple and cost-effective urban transportation systems. However, although these systems have some interesting features, they present some drawbacks, which limit their use in the field of UTSs. In some of these solutions, the "rails" are composed of permanent magnets distributed along the guideway. Even though it was demonstrated that the cost of the PMs has a marginal effect on the cost of the guideway as a whole, some safety issues should be considered in order to avoid possible derailment due to tampering of the rails with some ferromagnetic materials, which could be thrown on the permanent magnets.
A different approach characterizes the American version of Maglev (AMLEV) [4]-[11], developed by Oleg Tozoni in the USA since 1992. The AMLEV is based on the interaction between a system of permanent magnets installed on the vehicle, and steel cores positioned along the guideway. This configuration, allows reducing the safety problems, due to the absence of the PMs along the guideway. Furthermore, if the speed of the vehicle exceeds a theoretical value of about 20-25 $\mathrm{m} / \mathrm{s}$, the inventor demonstrated that the system is self-stabilizing in terms of lateral forces.

In this paper, the main characteristics of an urban transportation system are synthesized and the advantages in using a maglev technology are described. Then, a FEM model of the AMLEV system is developed in order to obtain both the levitating and lateral magnetic forces. Finally, the application of the AMLEV technology to a low speed urban transportation system is described and some details in terms of energy consumption with respect to conventional wheel-on-rail systems are given.

\section{Charactheristics of A URBAN Transportation System}

Fig. 1 shows the main subsystems, which compose a Urban Transportation System: a) the guideway; b) the vehicle; c) the levitation and guidance systems; d) the propulsion system; e) the electrical system; and f) the control system. In the following, the main differences of the vehicle, and of the levitation and guidance systems between a conventional and a maglev-based UTS are synthesized.

In conventional UTSs, the vehicle is characterized by a rigid structure capable to concentrate the weight and the load on the wheels shafts. In a Maglev Urban Transportation System (MUTS), instead, the magnetic suspension is positioned along all the vehicle length and it allows distributing the load. Consequently, both the vehicle complexity and weight can be reduced [12]. The typical empty vehicle weight is in the range between 4 and 20 metric tons, and its dimensions are about 1018 meters (length), 2.5-3.2 meters (width) and 3.0-3.5 meters (height). As for the levitation and guidance systems, a magnetic device capable to produce a levitating force and a lateral guidance force substitutes the wheel-on-rail system in a MUTS. 


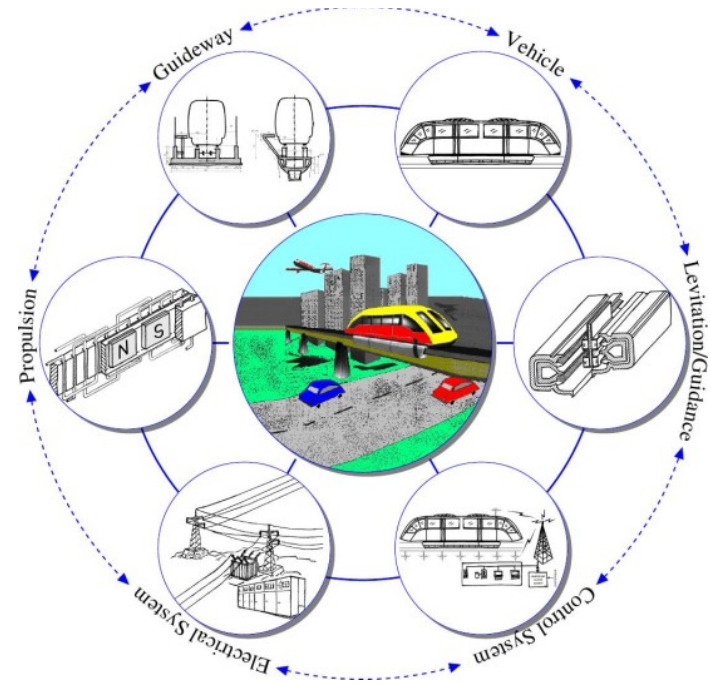

Fig. 1. Overview of a Maglev Urban Transportation System

Three main types of solutions have been proposed in the past to levitate and guide a MUTS vehicle. The first type is based on conventional electromagnets (EMS); it is able to produce forces tending to attract the vehicle to the rails. In order to maintain a constant clearance between the vehicle and the rails, the system uses a servo control mechanism to adjust the electromagnet current. The second type uses superconducting magnets (EDS); it produces forces by the interaction between the high magnetic field of a set of primary (superconducting) magnets and currents induced by the movement of the whole system on secondary coils, strategically positioned on the guideway. The third type is based on permanent magnets (PMS); in this solution, the levitation is obtained by exploiting the natural repulsive force of two oppositely magnetized permanent magnet systems, the first one arranged below the vehicle, and the second PM system fixed along the guideway.

However, the main technical problems of such systems are respectively: the complexity of the control system for the EMS; the cooling system required to maintain the correct cryogenic temperature of the superconducting magnets in the EDS, and the intrinsic instability of passive magnetic systems for the PMS.

\section{THE AMLEV SYSTEM}

The AMLEV is a hybrid system, which uses permanent magnets and iron cores. It was developed and patented by Oleg Tozoni since 1992 [4]-[11], as an alternative to the EMS and EDS systems for high speed ground transportation. For the sake of clarity, the main characteristics of this system are here briefly described. As shown in figs. 2a), 2b) and 2c) (respectively taken from [7], [6] and [5]), the AMLEV system comprises two different parts. The first one is composed of a set of rare-earth permanent magnets and it is positioned on the bottom surface of the levitated vehicle; the second part, instead, is made of iron cores, properly shaped and positioned on to the guideway and fixed with respect to the ground. When the PM are perfectly centered along both the $\mathrm{z}$ and $\mathrm{y}$ direction, the levitation force $F_{z}$ and the lateral (guidance) force $F_{y}$ equal zero. On the contrary, when the PM system is shifted down, a positive magnetic levitation force $F_{Z}$ is exerted on the system tending to bring the $\mathrm{PM}$ in its original position. As for the lateral direction, if the PM system is shifted along y-axis (+ve or -ve), a lateral force $F_{y}$ of the same sign is produced. This destabilizing force tends to attract the PM system onto the steel cores. Anyhow, the AMLEV inventor exploited the nonlinear behavior of the ferromagnetic material in order to reduce the lateral destabilizing force. Furthermore, if the polarity of the PM is properly changed along the vehicle length, during the motion of the system, eddy currents are induced, in an aluminum screen, placed around the steel cores. This effect allows to further reduce the destabilizing force, and when the vehicle reaches a suitable speed (usually above $20-25 \mathrm{~m} / \mathrm{s}$ ), the guidance units (elements 1 and 4 in fig. 2c)) are able to produce a stabilizing force which compensates the destabilizing forces of the levitating units (elements 2 and 3 in fig. 2c)). The system was investigated by using a detailed analytical model [6], useful for the optimization the device with respect to geometric and physical parameters. A working example with a vehicle carrying 100 passengers (total weight $25.000 \mathrm{~kg}$, length $22 \mathrm{~m}$ ), a permissible lateral disturbance of 50 $\mathrm{kN}$, moving at a maximum speed of about $150 \mathrm{~m} / \mathrm{s}$, was described. The inventor declared: "A new type of magnetodynamic suspension system has been developed. This system may be utilized in high speed ground public transportation as self-regulating magnetic suspension that ensures vehicle stability." [6].

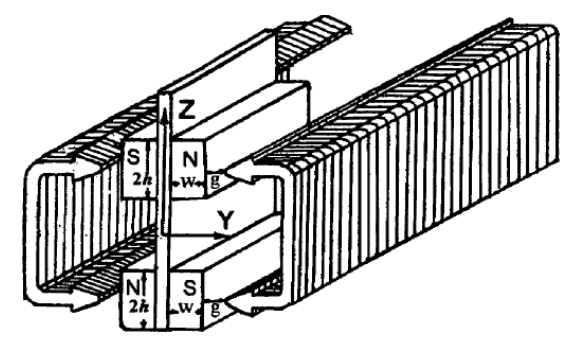

a) 3D schematic view of the AMLEV levitation unit (from [7])

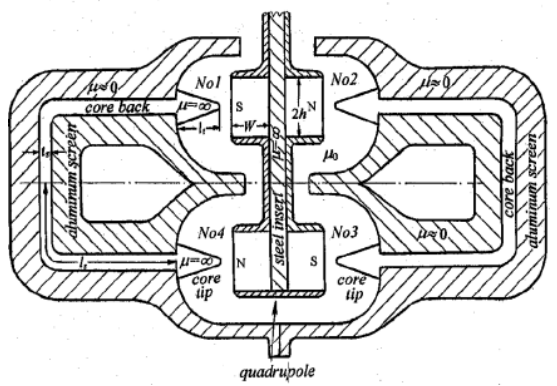

b) $2 D$ detailed view of the AMLEV levitation unit (from [6])

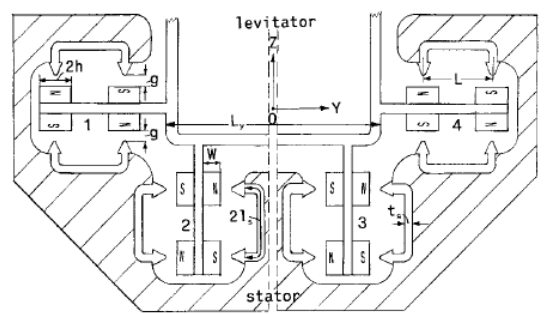

c) schematic view of the AMLEV levitation/guidance units (from [5])

Fig. 2. The AMLEV system developed by Oleg Tozoni 


\section{THE LOW SPEED APPLICATION}

In the field of Maglev Urban Transportation Systems, the maximum speed usually does not exceed $20 \mathrm{~m} / \mathrm{s}$. Furthermore, depending on the line length and the number of stops, the average speed could be well lower this value. Then, the condition of stability described in the previous paragraph, cannot be satisfied. Although in some documents Oleg Tozoni proposed a simplified variant of AMLEV in which the lateral guiding units were substituted by means a system of horizontal wheels capable to compensate the destabilizing forces, this solution was only sketched and planned for high-speed applications.

In order to investigate the possible use of AMLEV in low speed systems, a numerical model of the device has been developed. It is based on a FEM code and several simulations have been performed in order to identify a suitable shape and dimensions of the steel cores, capable to increase the ratio between the levitating force $F_{Z}$ and the lateral destabilizing force $F_{y}$. Nowadays, FEM packages are able to take into account nonlinear characteristics as well as hysteresis behavior of materials [13]-[15]. A high ratio $\epsilon=F_{z} / F_{y}$ allows designing an effective guidance system, able to counterbalance the destabilizing force. Two possible solutions are considered. The first one uses a mechanical constraint to keep the vehicle suspended in the region of levitation and to prevent horizontal deviations from the prescribed trajectory. To achieve this effect, the vehicle is equipped with stabilizing horizontal wheels installed in a row at each vehicle side. These wheels roll along special guiding paths, made of plastic or stiff rubber and fixed along the lateral guideway walls. Since the wheels should be durable and light at the same time, they can be made either of high performance solid polyurethane industrial material or of steel. However, it is important to note that the contact between the horizontal wheels and the guiding paths is not continuously and when it happens the contact force between the wheels and the guide is a fraction of the weight of the vehicle.

A second solution exploits the capability of the propulsion system, usually a Linear Synchronous Motor (LSM), to produce also a lateral stabilizing force. The interaction between the LSM windings and the PM fixed below the vehicle allows correcting the horizontal trajectory of the vehicle, keeping it in the center position. This last approach requires several accurate position sensors and a complex real time control system. Since the improvement of the overall performance is marginal for this type of vehicle, while the complexity and costs increase, it will not be considered in the following, and the use of linear induction motor for propulsion system is assumed [16]-[21].

Figure 3 shows the schematic view of a portion of vehicle and guideway, with the right-side levitating unit and the horizontal wheel, used to counterbalance the destabilizing force.

Figure 4 shows the geometry of the FEM model used to perform the simulations and to characterize the levitation unit in terms of levitating and destabilizing lateral forces. In the same figure, the main dimensions of the system are detailed.

In fig. 5, as an example of results, the map of the magnetic flux density in the system, when $\Delta z=-10 \mathrm{~mm}, \Delta y=2 \mathrm{~mm}$ is shown.

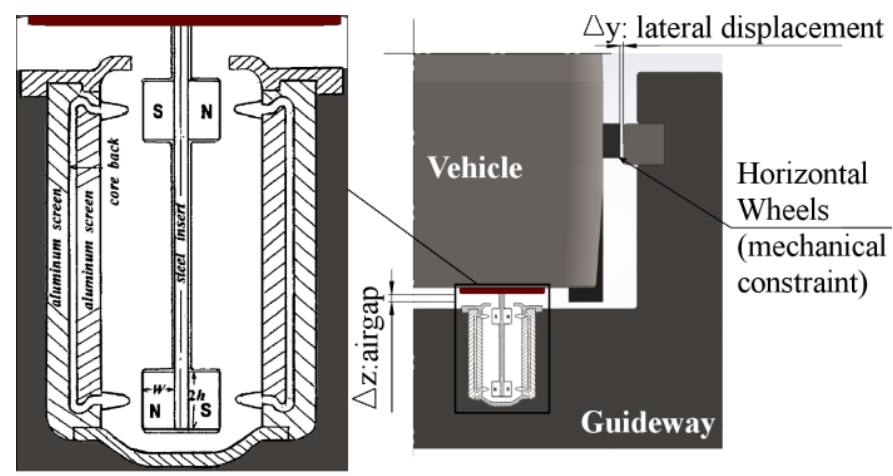

Fig. 3. Schematic view of a portion of vehicle and guideway, with the rightside levitating unit and the horizontal wheel, used to counterbalance the destabilizing force.

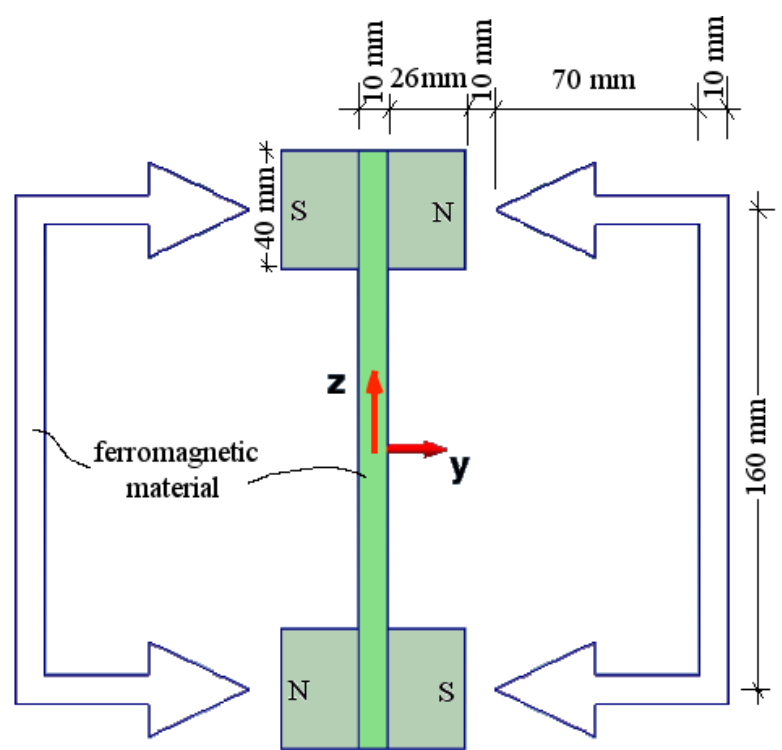

Fig. 4. Schematic view of the levitating unit with the main dimensions.

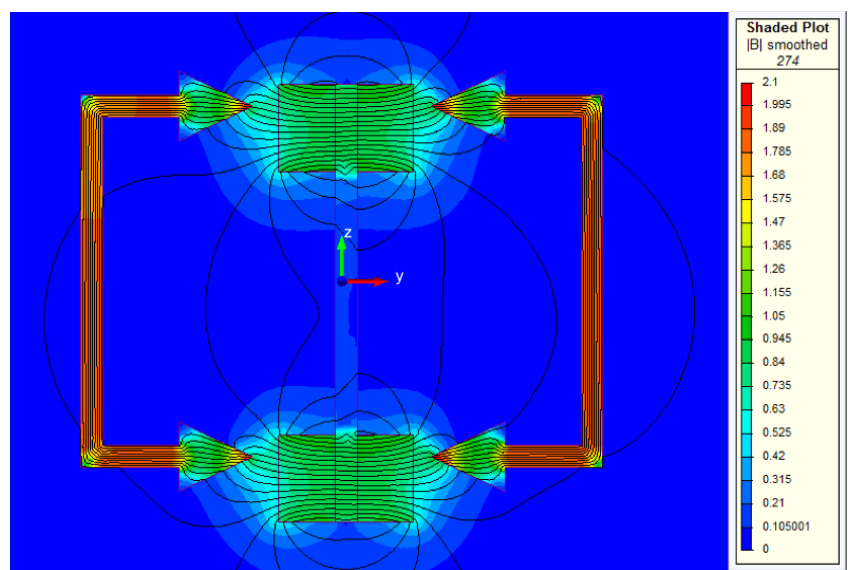

Fig. 5. Map of the magnetic flux density for $\Delta z=-10 \mathrm{~mm}, \Delta y=2 \mathrm{~mm}$. 
Figure 6 shows the levitation force $F_{z}$ vs the vertical shift $\Delta z$ with respect to the centered position, for several values of the lateral shift $\Delta y$. Figure 7 shows the lateral force $F_{y}$ vs $\Delta y$, for several values of the vertical shift $\Delta z$.

For a given value of remnant magnetic flux density of the PM $\left(B_{r}=1.3 T\right)$ and with a M5 grain oriented electrical steel as ferromagnetic material, the profile of the core tips and the thickness of the back cores shown in figure, allow to obtain a ratio $\epsilon=F_{z} / F_{y} \simeq 4$ (@ $\left.\Delta z=-15 \mathrm{~mm}, \Delta y=2 \mathrm{~mm}\right)$.

However, as discussed in [5] and [6] this ratio can be increased up to $8-10$, by optimizing the core tips profile and back cores thickness.

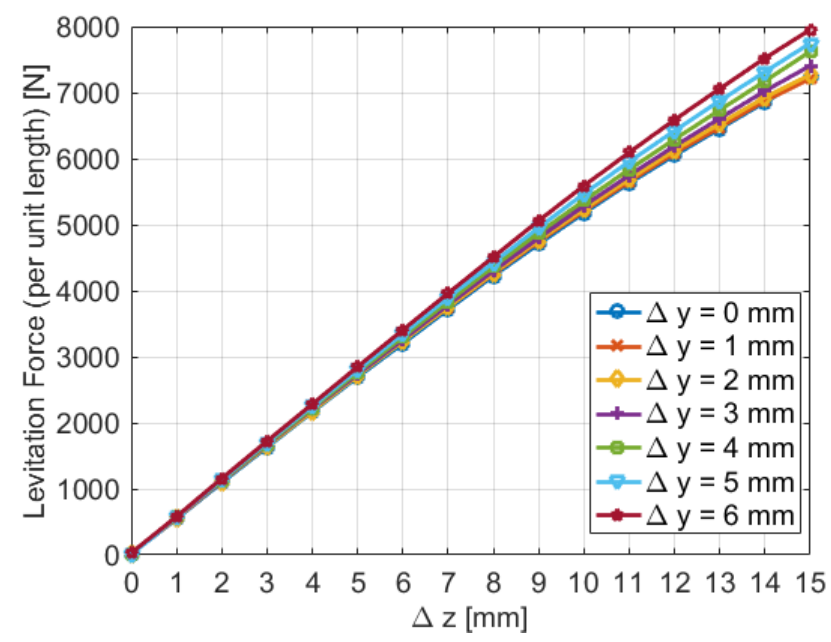

Fig. 6. Levitation Force $F_{z}$ vs $\Delta z$, as a function of the lateral shift $\Delta y$

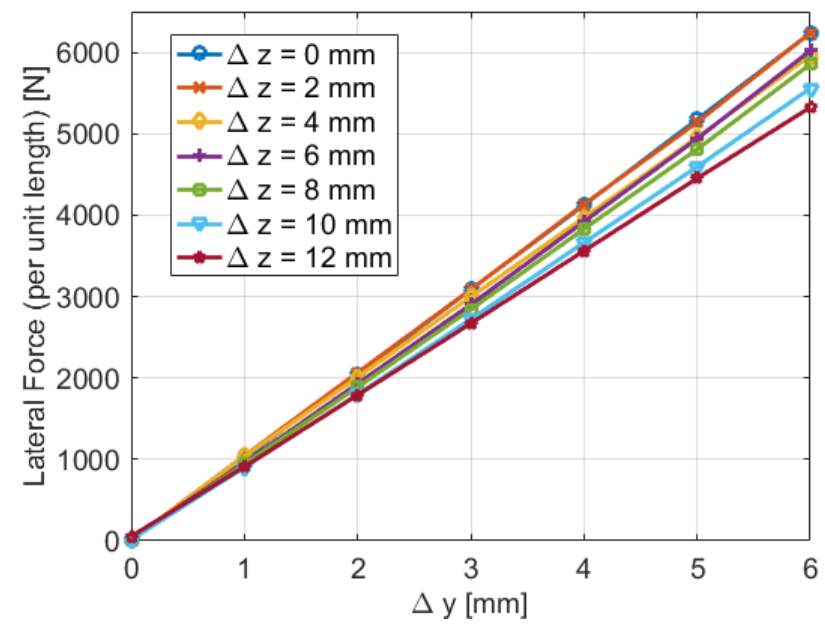

Fig. 7. Lateral Force $F_{y}$ vs $\Delta y$, as a function of the vertical shift $\Delta z$

\section{COMPARISON BETWEen CONVENTIONAL AND MAGLEV URBAN TRANSPORTATION SYSTEM}

A comparison between a conventional UTS and the proposed maglev UTS in terms of energy requirements has been performed through a numerical simulation model, based on
Modelica language [22]. It must be preliminarily specified that energy flows analysis has required a simulation tool able to solve the network equations, the vehicle dynamic equations, the driver and different running phases such as acceleration, constant speed run, coasting and braking. In the considered approach, the system includes electrical feeding substations (ESSs), the contact line, and vehicles that draw or deliver power. Subsystems have been modelled by lumped components connected to each other, as described in [23], [24]. Similar approaches are also found in literature [25], [26]. The model, firstly developed to simulate conventional tramways, has been modified to take into account the main features of the MUTS described in the previous paragraphs.

TABLE I. MAIN CHARACTERISTICS OF THE SYSTEM UNDER STUDY

\begin{tabular}{|l|c|}
\hline Line length & $20 \mathrm{~km}$ \\
\hline Number of Electrical substations & 5 \\
\hline Number of stops (including the two terminals) & 14 \\
\hline Number of operating vehicles & 4 \\
\hline Vehicle empty mass & $4000 \mathrm{~kg}$ \\
\hline Full load mass & $5700 \mathrm{~kg}$ \\
\hline Max speed & $10 \mathrm{~m} / \mathrm{s}$ \\
\hline Aerodynamic drag coefficient & 0.8 \\
\hline Frontal area & $5 \mathrm{~m}^{\wedge} 2$ \\
\hline Rolling resistance coefficient (polyurethane-steel) & 0.0057 \\
\hline Rolling resistance coefficient (steel-steel) & 0.0025 \\
\hline
\end{tabular}

The comparison refers to a real tramline with a total length of about $20 \mathrm{~km}$, with five electrical substations, 14 stops (including the two terminals) and four operating vehicles [27] - [32]. The maximum speed between stops has been fixed to $10 \mathrm{~m} / \mathrm{s}$. The main characteristics of the system under study have been described in Table I.

The analysis was performed to evaluate the difference in terms of energy consumption for different operating conditions. In fact, when a high number of stops is considered, inertial contribution tends to become the most relevant. On the contrary, when a reduced number of stops is considered, the energy variation mainly depends on the motion resistance. Simulations were carried out considering that the systems send their braking energy into the electrical system, as long as its voltage does not overcome the maximum allowed limit. Table 2 reports the preliminary results obtained when 4 stops and 14 stops are simulated.

Results may be interpreted also by evaluating the energy saving for the different variants in terms of number of stops. As visible, at equal number of stops, energy saving in a Maglev UTS w.r.t. the conventional one tends to increase by reducing the lateral displacement. The reduction in terms of the energy delivered by ESSs ranges from 5.9\% (14 stops, $\Delta y=3 \mathrm{~mm}$, polyurethane wheels) up to $13.5 \%$ (4 stops, $\Delta y=0 \mathrm{~mm}$, steel wheels). However, for the same configuration, the number of stops has little influence on the obtained values. In fact, braking energy recovery capability tends to flatten the differences between 4 and 14 stops, since it is however possible to recover at least part of the braking energy. 
TABLE II

ENERGY DELIVERY ON ONE TYPICAL HOUR, BRAKING ENERGY RECOVERY: PRELIMINARY RESULTS

\begin{tabular}{|l|c|c|c|c|}
\cline { 2 - 5 } \multicolumn{1}{c|}{} & \multicolumn{2}{c|}{4 stops } & \multicolumn{2}{c|}{14 stops } \\
\cline { 2 - 5 } \multicolumn{1}{c|}{} & $\mathrm{kW}$ & $\%$ & $\mathrm{~kW}$ & $\%$ \\
\hline Conventional UTS & 25.3 & - & 21.9 & - \\
\hline $\begin{array}{l}\text { Maglev UTS } \\
\begin{array}{l}\Delta y=3 \mathrm{~mm} \\
\text { (polyurethane-steel) }\end{array}\end{array}$ & 23.7 & -6.3 & 20.6 & -5.9 \\
\hline $\begin{array}{l}\text { Maglev UTS } \\
\begin{array}{l}\Delta y=3 \mathrm{~mm} \\
\text { (steel-steel) }\end{array}\end{array}$ & 22.7 & -10.3 & 19.7 & -10.0 \\
\hline $\begin{array}{l}\text { Maglev UTS } \\
\begin{array}{l}\Delta y=0 \mathrm{~mm} \\
\text { (vehicle perfectly } \\
\text { centered along the path) }\end{array}\end{array}$ & 21.9 & -13.5 & 19.2 & -12.3 \\
\hline
\end{tabular}

\section{CONCLUSiOnS}

This paper describes the application of the maglev technology to a low speed Urban Transportation System. The magnetic device used to levitate the vehicle was derived from the AMLEV system, developed by Oleg Tozoni since 1992 for high speed transportation systems. Some preliminary results in terms of energy consumption between conventional UTS and the proposed MUTS shows that the latter allows increasing the braking energy recovery during standard operative conditions.

\section{REFERENCES}

[1] R. Thornton, T. Clark, B. Perreault, J. Wieler, S. Levine, "An M3 Maglev System for Old Dominion University", 20th International Conference on Magnetically Levitated Systems and Linear Drives (Maglev 2008), San Diego, 2008.

[2] S. Gurol, B. Baldi, R. F. Post, "Overview of the General Atomics Low Speed Urban Maglev Technology Development Program", The 17th International Conference on Magnetically Levitated Systems and Linear Drives, Lausanne, Switzerland, September 3-5, 2002.

[3] Hyung-Woo Lee, Ki-Chan Kim and Ju Lee, "Review of maglev train technologies," in IEEE Transactions on Magnetics, vol. 42, no. 7, pp. 1917-1925, July 2006.

[4] O. V. Tozoni, "Amlev-a self-regulating version of Maglev," in IEEE Transactions on Magnetics, vol. 37, no. 6, pp. 3925-3933, Nov 2001.

[5] O. V. Tozoni, "Designing a magnetodynamic stable suspension system," in IEEE Transactions on Magnetics, vol. 35, no. 5, pp. 4268-4274, Sep 1999.

[6] O. V. Tozoni, "New stable magnetodynamic suspension system," in IEEE Transactions on Magnetics, vol. 35, no. 2, pp. 1047-1054, Mar 1999.

[7] O. V. Tozoni, "Self-regulating magneto-dynamic system for high speed ground transportation vehicle", US Patent 8,047,138. November 2011.

[8] O. V. Tozoni, "Magnetodynamic levitation and stabilizing self-regulating system", US Patent 5,652,472, July 29, 1997.

[9] O. V. Tozoni, "Magnetic levitation self-regulating systems having enhanced stabilization forces", US Patent 5,319,275, June 7, 1994.

[10] O. V. Tozoni, "Magnetic levitation self-regulating systems", US Patent $5,218,257$, June 8,1993

[11] O. V. Tozoni, "Self-adjusting magnetic guidance system for levitated vehicle guideway", US Patent 5,140,208, August 18, 1992

[12] R. D. Thornton, "Efficient and Affordable Maglev Opportunities in the United States," in Proceedings of the IEEE, vol. 97, no. 11, pp. 1901 1921, Nov. 2009.
[13] Cardelli, E., Faba, A., Laudani, A., Riganti Fulginei, F., Salvini, A., “A neural approach for the numerical modeling of two-dimensional magnetic hysteresis", (2015) Journal of Applied Physics, 117 (17)

[14] Cardelli, E., Faba, A., Laudani, A., Pompei, M., Quondam Antonio, S., Fulginei, F.R., Salvini, A., "A challenging hysteresis operator for the simulation of Goss-textured magnetic materials", (2017) Journal of Magnetism and Magnetic Materials, 432, pp. 14-23.

[15] Cardelli, E., Faba, A., Laudani, A., Quondam Antonio, S., Fulginei, F.R., Salvini, A., "Computer Modeling of Nickel-Iron Alloy in Powe Electronics Applications", (2017) IEEE Transactions on Industrial Electronics, 64 (3), art. no. 7529045, pp. 2494-2501.

[16] M. Caruso, G. Cipriani, V. Di Di, R. Miceli., C. Nevoloso, "Experimental characterization and comparison of TLIM performances with differen primary winding connections," Electric Power Systems Research, 146, pp. 198-205, 2017.

[17] G. Cipriani, M. Corpora, D. Curto, V. Di Dio, V. Franzitta, M. Trapanese, "An electromagnetic generator for MAGLEV transportation systems," 2015 International Conference on Renewable Energy Research and Applications, ICRERA 2015, pp. 1523-1526, 2016.

[18] V. Di Dio, G. Cipriani, M. Corpora, D. Curto, M. Trapanese, “A Ferrite Tubular Linear Motor (FTLM): Analysis and design,” 2015 IEEE International Magnetics Conference, INTERMAG 2015.

[19] G. Cipriani, V. Di Dio, M. Corpora, V. Franzitta, D. Curto, M. Trapanese, "The role of the effect of manufacturing tolerances on a tubular linear ferrite motor," 2015 IEEE International Magnetics Conference, INTERMAG 2015, art. no. 7157304, 2015.

[20] V. Di Dio, G. Cipriani, R. Miceli., R. Rizzo, "Design criteria of tubular linear induction motors and generators: a prototype realization and its characterization," Leonardo Electronic Journal of Practices and Technologies, 12 (23), pp. 19-40, 2013.

[21] V. Di Dio, M. Montana, "State of art of tubular linear induction motor," Proceedings of the Mediterranean Electrotechnical Conference MELECON, 1, pp. 285-288, 1996.

[22] P. Fritzson, "Introduction to Modeling and Simulation of Technical and Physical Systems with Modelica”, Wiley-IEEE Press, 2011.

[23] M. Ceraolo, M. Conte, R. Giglioli, G. Lutzemberger, M. Pasquali: "Use of electrochemical storage in substations to enhance energy and cost efficiency of tramways", AEIT Annual Conference, Oct. 2013, Mondello.

[24] M. Ceraolo, G. Lutzemberger, "Stationary and on-board storage systems to enhance energy and cost efficiency of tramways", Journal of Powe Sources, vol. 264, pp. 128-139, 2014.

[25] L. Pugi, M. Malvezzi, S. Papini, S. Tesi, "Simulation of braking performance: The AnsaldoBreda EMU V250 application", Proceedings of the Institution of Mechanical Engineers, Part F: Journal of Rail and Rapid Transit, 229 (2), pp. 160-172, 2015.

[26] L. Pugi, M. Malvezzi, S. Papini, G. Vettori, "Design and preliminary validation of a tool for the simulation of train braking performance", Journal of Modern Transportation, 21 (4), pp. 247-257, 2013.

[27] M. Ceraolo, R. Giglioli, G. Lutzemberger, A. Bechini: "Cost effective storage for energy saving in feeding systems of tramways", International Electric Vehicle Conference (IEVC), 2014 IEEE, 17-19 Dec. 2014.

[28] S. Barsali, P. Bolognesi, M. Ceraolo, M. Funaioli, G. Lutzemberger: "Cyber-Physical Modelling of Railroad Vehicle System using Modelica Simulation Language", Railways 2014, 8-11 Apr. 2014.

[29] M. Ceraolo, M. Funaioli, G. Lutzemberger, M. Pasquali, D. Poli, L. Sani: "Electrical Storage for the Enhancement of Energy and Cost Efficiency of Urban Railroad Systems", Railways 2014, 8-11 Apr. 2014.

[30] M. Ceraolo, G. Lutzemberger, T. Huria: "Experimentally-Determined Models for High-Power Lithium Batteries", SAE Technical Paper 201101-1365, 2011, issn: 0148-7191, doi: 10.4271/2011-01-1365

[31] M. Ceraolo, G. Lutzemberger, M. Marracci, "High power Lithium Batteries usage in hybrid vehicles", Vehicle Power and Propulsion Conference (VPPC), 1-3 Sept. 2010.

[32] M. Ceraolo, G. Lutzemberger, D. Poli, "Aging evaluation of high power lithium cells subjected micro-cycles", Journal of Energy Storage, vol. 6, pages $116-124,2016$ 